\title{
ASSESSMENT OF HEMATOLOGICAL PROFILE OF NEWBORN AT BIRTH, BORN TO MOTHERS WITH GESTATIONAL HYPERTENSION, PREECLAMPSIA AND ECLAMPSIA SYNDROME
}

\author{
Prekshya L Prakash¹, P. Sunil Kumar², M. Venkata Murthy33, K.R. Haricharan
}

\section{HOW TO CITE THIS ARTICLE:}

Prekshya L Prakash, P Sunil Kumar, M Venkata Murthy, KR Haricharan. "Assessment of hematological profile of newborn at birth, born to mothers with gestational hypertension, preeclampsia and eclampsia syndrome". Journal of Evolution of Medical and Dental Sciences 2013; Vol2, Issue 34, August 26; Page: 6360-6369.

ABSTRACT: BACKGROUND: Gestational hypertension, preeclampsia and eclampsia syndrome is a multi system disorder associated with adaptive changes in the fetal circulation and causes a marked imbalance in the haemostatic system of the mother and the neonate. These babies may have a spectrum of hematological changes and can lead to serious neonatal complication like sepsis and bleeding manifestations including intracranial hemorrhage. Therefore early hematological screening of these infants is recommended. AIMS: The present study was done to find out the hematological profile of babies born to mothers with gestational hypertension, preeclampsia and eclampsia. SETTINGS AND DESIGN: This is a prospective study conducted at Sri Adichunchanagiri Institute of Medical Sciences from January 2011 to June 2012. METHODS AND MATERIAL: The case group comprised of 75 neonates born to mothers diagnosed either with gestational hypertension, preeclampsia and eclampsia while controls comprised of 75 apparently healthy newborns born to normotensive mothers without maternal complications, born during the same period. $2 \mathrm{ml}$ of cord blood anti coagulated with EDTA was collected from these babies and complete haemogram, peripheral blood smear examination and nucleated red blood cell count were studied. Statistical Analysis used: The Statistical software namely SAS 9.2, SPSS 15.0, Stata 10.1, MedCalc 9.0.1, Systat 12.0 and R environment ver.2.11.1 were used for the analysis of the data, Microsoft word and Excel have been used to generate graphs, tables etc. RESULTS: Mothers with gestational hypertension, preeclampsia and eclampsia syndrome had a higher number of premature and small for gestational age babies. Total leukocyte count, neutrophil count, absolute neutrophil count and platelet count were significantly decreased in these babies. The number of nucleated red blood cells seen in the peripheral smear was significantly higher in these babies. There was a significantly higher mean corpuscular volume, while the red cell count and the mean corpuscular hemoglobin were only suggestive of statistical significance between the cases and the controls. CONCLUSION: As these babies are more prone for development of leucopenia, neutropenia and thrombocytopenia during the early neonatal period, these babies should be closely monitored and managed in order to decrease the perinatal morbidity and mortality.

KEY WORDS: Gestational hypertension, Preeclampsia, Eclampsia syndrome, Hematological profile, Newborn.

INTRODUCTION: Gestational hypertension, preeclampsia and eclampsia syndrome is a multisystem disease and a threat to the well being of both the mother and her newborn child. It contributes significantly to the cause of maternal and perinatal morbidity and mortality. 


\section{ORIGINAL ARTICLE}

Presence of severe hypertension during pregnancy causes a marked imbalance in maternal homeostasis and an unfavorable environment to the fetus. The obstetrical studies have well documented the vascular, hematological, and biochemical abnormalities in the mother, but the effect of the disease process on the fetus and especially on the neonate are incompletely characterized.

The neonatal consequences of maternal hypertension are complicated by the administration of antihypertensive and antiepileptic medications to the mother. Thus the perinatal outcome may be influenced by both the maternal disease and pharmacological intervention. They may also suffer from the consequences of high rate of operative deliveries.

Babies born to mothers with pregnancy induced hypertension are susceptible to illness or death because of immaturity, physical disorders or complications during or after birth. The newborns of hypertensive mothers have a significantly higher incidence of somatic growth retardation, thrombocytopenia, leucopenia, neutropenia, low apgar scores, delayed adaptation, patent ductus arteriosus and gastrointestinal hypomotility. Apgar scores, platelet count, white blood cell (WBC) count, neutrophil count, and weight percentile correlate with the severity of maternal platelet and enzyme abnormalities ${ }^{1}$.

These babies may have a spectrum of hematological changes which may add to the existing morbidity in them. Occurrence of severe neonatal thrombocytopenia was found to be significantly associated with low birth weight and prematurity2.

The differences in values in the hematological profile in neonates are so variable that it may be difficult to draw the line between normal and abnormal. Also the range is so wide that small changes that do not register in the general picture may contribute to wide variance in the final clinical profile.

Hematological abnormalities in infants born to hypertensive mothers can lead to serious neonatal complication like sepsis (higher in preterm than in term neonates) and bleeding manifestations including intracranial hemorrhage from platelet deficiency due to any cause ${ }^{3}$. Therefore early hematological screening of these infants is recommended.

Hence the purpose of this study is to identify the early hematological changes of the infants born to mothers with gestational hypertension, preeclampsia and eclampsia syndrome, so as to anticipate, diagnose and treat them early to decrease the perinatal morbidity and mortality.

MATERIALS AND METHODS: This prospective randomized case control study was conducted in the neonatology unit of the Department of Pediatrics, Sri Adichunchanagiri Institute of Medical Sciences, B.G. Nagara from January 2011 to June 2012. The case group included 75 neonates born to mothers whose blood pressure was more than or equal to $140 / 90 \mathrm{mmHg}$, detected after the twentieth week of pregnancy. They were classified as gestational hypertension (new onset non proteinuric Hypertension), preeclampsia (proteinuric Hypertension) and eclampsia (seizures that cannot be attributed to other causes in a woman with preeclampsia). Babies born with congenital malformations and those born to mothers with other problems like rhesus incompatibility, diabetes mellitus, severe anemia, hemophilia, chronic hypertension, renal disease, heart disease, connective tissue disease, nutritional and those who received aspirin were excluded from the study. Institutional review board approval was obtained for the study and written informed consent was taken from the parents for the study. The control group comprised apparently 75 healthy newborns born to normotensive mothers without maternal complications, born during the same period. 


\section{ORIGINAL ARTICLE}

Maternal details like age, parity, immunisation status, gestational age, onset of symptoms, blood pressure recording, presence of seizures and proteinuria, details of labour, mode of delivery and presence of complications if any during labour were also recorded. Baby details like name, sex, date of birth, time of birth, Apgar score, gestational age (by New Ballard's scoring system) were recorded. General and physical examination of the neonates was done, including anthropometric measurements.

$2 \mathrm{ml}$ of cord blood anti coagulated with EDTA was collected from these babies and Hemoglobin, Total and Differential counts, Platelet count and Red cell indices like packed cell volume (PCV), mean corpuscular volume (MCV), mean corpuscular hemoglobin (MCH), mean corpuscular hemoglobin concentration (MCHC) were estimated using automated cell counter method using SYSMEX KX-21 automated hematology analyser B2584 08/2007 Japan. Platelet count was confirmed by peripheral smear examination and REES ECKER method. Peripheral blood smear and nucleated RBC (nRBC) were examined using the smear stained with Leishman's stain.

Analysis of variance (ANOVA) has been used to find the significance of study parameters between three or more groups of patients, Student $t$ test (two tailed, independent) has been used to find the significance of study parameters on continuous scale between two groups on metric parameters. Leven1s test for homogeneity of variance has been performed to assess the homogeneity of variance. Chi-square/ Fisher Exact test has been used to find the significance of study parameters on categorical scale between two or more groups. Pearson's correlation has been used to show the relationship between the mothers and the babies values.

The Statistical software namely SAS 9.2, SPSS 15.0, Stata 10.1, MedCalc 9.0.1, Systat 12.0 and R environment ver.2.11.1 were used for the analysis of the data, Microsoft word and Excel have been used to generate graphs, tables etc.

RESULTS: Of the 75 mothers with gestational hypertension, preeclampsia and eclampsia syndrome in this study, 11 had eclampsia (14.7\%), 36 had preeclampsia (48\%) and 28 had gestational hypertension (37.3\%). In this study 11 mothers presented with convulsions, the others had symptoms like headache (41.3\%), blurring of vision (16\%), pallor (41.3\%) and all had pedal edema, with statistically significant $\mathrm{p}<0.001$.

The pregnancy and delivery details of cases and controls have been listed in table- 1 .

Albuminuria was present in 53 mothers in cases group and only 3 mothers in the control group. Of the 3 mothers in the control group who initially showed traces of albumin in their urine on subsequent testing were found to have no proteinuria prior to delivery, with statistically significant $\mathrm{p}<0.001$.

23 mothers whose pregnancy was complicated by gestational hypertension, preeclampsia and eclampsia syndrome received magnesium sulphate before delivery.

In this study $1 / 4^{\text {th }}$ of the babies were born prematurely. Among these $25 \%(5 / 20)$ of were less than 34 weeks, while 75\% (15/20) were born between 34-36 weeks and rest were term gestation. In this study highest rate (54.4\%) of prematurity was observed in neonates born to eclamptic mothers, while $27.7 \%$ were born to pre-eclamptic mothers. Prematurity was least commonly observed in the gestational hypertension group with a rate of $17.9 \%$.

19 of the cases had intrauterine growth retardation, among them $15.8 \%, 57.9 \%$ and $26.3 \%$ of babies were born to mothers with gestational hypertension, preeclampsia and eclampsia 


\section{ORIGINAL ARTICLE}

respectively. While the rest (56 cases) had normal intrauterine growth, among them $44.6 \%, 44.6 \%$ and $10.8 \%$ were born of gestational hypertension, pre-eclamptic and eclamptic mothers respectively. This observation shows that gestational hypertension, preeclampsia and eclampsia syndrome category was significantly associated with intrauterine growth retardation with $\mathrm{p}=0.04$. Among the 19 babies with IUGR, 11 babies and 8 babies had asymmetrical and symmetrical IUGR respectively.

The comparison of babies hematological profile in cases and control groups have been documented in table-2. It shows nRBC, total leucocyte count (TLC), neutrophils, lymphocytes, absolute neutrophil count (ANC) and platelet count is severely affected, and it is statistically significant.

In our study we observed that the mean hemoglobin, PCV and red cell count were lower in the babies of eclamptic and pre-eclamptic mothers than in gestational hypertension mothers and it is shown in table-3. It is shown that the mean platelet count was lowest in babies of eclamptic mothers (1.29lakh/ $\mathrm{mm}^{3}$ ) followed by those of pre-eclamptic $\left(1.40 \mathrm{lakh} / \mathrm{mm}^{3}\right)$ and gestational

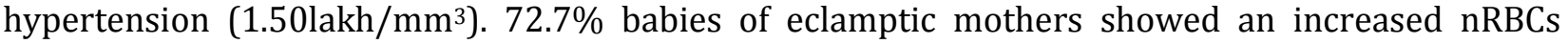
while $58.3 \%$ and $28.6 \%$ babies of pre-eclamptic and gestational hypertension had increased nRBCs respectively. Leucopenia was seen in $63.9 \%, 45.3 \%$ and $39.3 \%$ babies of pre-eclamptic, eclamptic and gestational hypertension mothers respectively. Neutropenia was seen in $17.9 \%, 30.6 \%$ and $27.5 \%$ babies of pre-eclamptic, eclamptic and gestational hypertension mothers respectively. And it was statistically significant with $\mathrm{p}<0.001$.

Table-4 shows number of babies born to mothers with gestational hypertension, preeclampsia and eclampsia syndrome presenting with thrombocytopenia was higher with higher levels of maternal systolic and diastolic blood pressure.

DISCUSSION: Hypertensive disorders are one of the most common obstetric complications in pregnancy. These disorders provide great challenges for obstetricians and neonatologists because they are associated with a number of adverse maternal outcomes and short and long term neonatal complications. Gestational hypertension, preeclampsia and eclampsia syndrome have important implications for the mother and her baby, suggesting that it is not a simple gestational disorder but a clinical syndrome involving important maternal and fetal vascular alterations that can persist and cause diseases in later life ${ }^{4}$.

Newborn infants exposed to gestational hypertension, preeclampsia and eclampsia syndrome present with short term morbidity, mainly respiratory diseases such as respiratory distress syndrome, bronchopulmonary dysplasia and gastrointestinal problems. These problems could be related not just to gestational hypertension, preeclampsia and eclampsia itself but also to prematurity or intrauterine growth restriction, which frequently occur in this maternal disease.

There is concern about the possible relationship between gestational hypertension, preeclampsia, eclampsia syndrome and sepsis, and a higher incidence of sepsis was reported in preterm infants of mothers who have HELLP syndrome (hemolysis, elevated liver enzymes, low platelet count), gestational hypertension and severe preeclampsia compared to normotensive mothers ${ }^{5}$. 6 . In our study 6 babies developed proven sepsis within 72 hours of life requiring admission and management in the neonatal intensive care unit. 4 of these were preterm babies while 2 babies were of term gestation. All 6 babies recovered following appropriate treatment and 


\section{ORIGINAL ARTICLE}

were discharged. 4 babies in our study ( 3 term and 1 preterm) developed probable sepsis and were also discharged following appropriate treatment. All of these 10 babies had neutropenia as well as thrombocytopenia.

Hemoglobin concentration showed a mean of $14.83 \mathrm{~g} / \mathrm{dl}$ which was comparable to that observed by Saarinen, et al. ${ }^{7}$ and Marwaha, et al. ${ }^{8}$. The hematocrit observed in this study was 44.52\% in cases and $45.50 \%$ in controls as compared to Marwaha, et al. ${ }^{8}$ (49.4\%) and Saarinen, et al. ${ }^{40}$ (35$59 \%)$. MCV (107.96 $\pm 7.47 \mathrm{fl}), \mathrm{MCH}(36.13 \pm 2.76 \mathrm{pg})$ and MCHC $(33.44 \pm 1.71 \mathrm{~g} / \mathrm{dl})$ all correlated well with Saarinen, et al.7. There was no significant difference seen in hemoglobin concentration, PCV, MCH or MCHC between the cases and controls in our study but MCV was found to be higher in case babies when comparable to controls and this observation was also similar to that reported by Sivakumar, et al. ${ }^{9}$ which may be due to larger size of RBCs in preterm infants. In our study we observed that the mean hemoglobin, PCV and red cell count were lower in the babies of eclamptic and pre-eclamptic mothers than in gestational hypertension mothers.

In this study we noted an increased number of nRBCs seen in the infants born to mothers with gestational hypertension, preeclampsia and eclampsia syndrome with a mean of 13.33/100 WBCs as against 2.44/100 WBCs in the controls. This difference was found to be of strong statistical significance with $\mathrm{p}<0.001$. Our finding was comparable with that of study done by Sivakumar, et al. ${ }^{9}$ and Shivhare, et al.10. Thus increased number of nRBCs was seen predominantly in babies of eclamptic and pre-eclamptic mothers than in mothers with gestational hypertension. This finding in our study correlates well with Philip, et al.11 who observed that the degree and duration of hypertension and hypoxemia was directly proportional to the increasing nRBC counts. Philip, et al. ${ }^{11}$ have postulated that elevated $\mathrm{nRBC}$ counts may reflect chronic intrauterine hypoxia although it is not clear what duration of hypoxemia is required to produce an elevated nRBC count. The rise of fetal hemoglobin and nRBC in the toxemic group is likely to be due to fetal anoxia as placental circulation in such cases is decreased to one third of that in normal pregnancy ${ }^{11}$. Tissue hypoxia leads to elevated levels of erythropoietin, which in turn results in stimulation of erythropoiesis and increased number of circulating nRBCs.

The most significant difference found in our study was the presence of thrombocytopenia in the babies born to mothers with gestational hypertension, preeclampsia and eclampsia syndrome. Thrombocytopenia was present in $57.3 \%$ of our cases which was almost twice of that observed in other studies, Brazy, et al. ${ }^{1}$, Bhat, et al. $^{2}$ and Fraser, et al. ${ }^{12}$. However Pritchard et al. ${ }^{13}$ have documented thrombocytopenia in only $4.2 \%$ of babies even though $30 \%$ of mothers had thrombocytopenia. In the present study thrombocytopenia was observed in $10.6 \%$ of the controls and this observation was comparable to that of Brazy, et al. ${ }^{1}$ who observed thrombocytopenia in $11 \%$ of the controls. Out of the 43 babies having thrombocytopenia, 32 (42.7\%) babies had a platelet count less than 1 lakh/ $\mathrm{mm}^{3}$ while the 11 (14.7\%) other babies with thrombocytopenia had counts between 1-1.5 lakhs $/ \mathrm{mm}^{3}$. In our study we were able to obtain a statistically significant correlation $(\mathrm{P}=0.028)$ between the infants platelet count and the maternal platelet count. When the mothers platelet count was in the range of 1-1.5 lakhs $/ \mathrm{mm}^{3}, 1.5-2$ lakhs $/ \mathrm{mm}^{3}, 2-3$ lakhs $/ \mathrm{mm}^{3}$ and $>3$ lakhs $/ \mathrm{mm}^{3}$, thrombocytopenia was seen in $11,11,24,4$ babies respectively. This observation was comparable to that of Brazy, et al. ${ }^{1}$ who have noted that the degree of thrombocytopenia in the infant was significantly related to the depression in maternal platelet counts. Severe neonatal thrombocytopenia $<50,000 / \mathrm{mm}^{3}$ can be associated with increased risk of hemorrhage ${ }^{14}$. However 


\section{ORIGINAL ARTICLE}

none of the babies in our study had any bleeding manifestations and there was no increased risk of intracranial hemorrhage following vaginal delivery/instrumental delivery.

The mean TLC and neutrophil count in this study was $9,310 / \mathrm{mm}^{3}$ and $4,412 / \mathrm{mm}^{3}$ respectively and it was less compared to controls, which correlates well with findings of Cristina, et al. ${ }^{15}$. And it was statistically significant with $\mathrm{p}<0.001$. Neutropenia has been well documented in the infants of mothers with gestational hypertension, preeclampsia and eclampsia syndrome (48\% noted by Doron et al. ${ }^{18}$ and $50 \%$ by Engle et al. ${ }^{19}$ ) and has been documented as one of the most common variety of congenital neutropenia. Although Engle et al. ${ }^{19}$ have not noticed a significant increase in the incidence of sepsis in these infants; Doron et al. ${ }^{18}$ have observed increased risk of nosocomial infection (12/42 babies developed sepsis). Neutropenia associated with maternal gestational hypertension, preeclampsia and eclampsia syndrome is generally transient and not associated with leukocyte shift to left or toxic granulations. Administration of G-CSF to these infants can increase the neutrophil count and decrease the risk of sepsis.

In this study $63.9 \%(23 / 36)$ of babies born to mothers with preeclampsia and $45.5 \%(5 / 11)$ of babies born to mothers with eclampsia had leucopenia, while the incidence of leucopenia in babies born to mothers with gestational hypertension was 39.3\% (11/28). Thus we observed leucopenia predominantly in infants whose mothers had preeclampsia and eclampsia. This observation was statistically suggestive of significance with a $\mathrm{p}<0.096$.

TLC as well as neutrophil count was significantly lower in cord blood from gestational hypertension, preeclampsia and eclampsia syndrome pregnancy. This finding seems to be a contra sense, as usually inflammation is characterized by leukocytosis and neutrophilia. Tsao, et al. ${ }^{16}$ demonstrated that gestational hypertension, preeclampsia and eclampsia syndrome is associated with low neutrophil count and granulocytes colony stimulating factor (G-CSF) levels in preterm newborns. We did not measure G-CSF in our samples, but in fact, the decrease in G-CSF may contribute to this leucopenia, as G-CSF is an important hematopoietic growth factor for granulocyte differentiation and proliferation ${ }^{17}$. Similar to Fraser, et al12, we also observed neutropenia predominantly in infants whose mothers had preeclampsia and eclampsia and it was $27.27 \%$ and $30.55 \%$ respectively, while the incidence of neutropenia in babies born to mothers with gestational hypertension was $17.85 \%$.

In this study a statistically significant correlation between the infants platelet count and severity of maternal hypertension was not obtained though the number of babies born to mothers with gestational hypertension, preeclampsia and eclampsia syndrome presenting with thrombocytopenia was higher with higher levels of maternal systolic and diastolic blood pressure. This finding was similar to that observed by S. Sivakumar et al. ${ }^{9}$

Gestational hypertension, preeclampsia and eclampsia syndrome especially preeclampsia is a major cause of maternal and perinatal morbidity and mortality worldwide. The most popular theory for the pathogenesis of preeclampsia describes a two stage process which ultimately results in a mismatch between the uteroplacental supply and the fetal demands.

Our study was an attempt to study the hematological changes that may be seen in neonates born to mothers with gestational hypertension, preeclampsia and eclampsia syndrome and to compare them with babies born to normotensive mothers.

In our study we observed many changes in the hematological profile of the babies born to mothers with gestational hypertension, preeclampsia and eclampsia syndrome when compared to 


\section{ORIGINAL ARTICLE}

the babies born to normotensive mothers. All the three cell lines (red cells parameters, white cell parameters and platelet counts) were more affected in babies of eclamptic and preeclamptic mothers than in mothers with gestational hypertension, suggesting that the severity as well as the duration of hypertension play a vital role in influencing the hematological parameters of babies born to mothers with gestational hypertension, preeclampsia and eclampsia syndrome and eventually the final neonatal and perinatal outcome.

Thus the chronic intrauterine hypoxia caused by gestational hypertension, preeclampsia and eclampsia syndrome may cause significant changes in the neonatal hematological profile. These changes should be kept in mind while interpreting the hematological values in these babies. Since babies born to mothers especially with pre-eclampsia and eclampsia are more prone for development of prematurity, low birth weight and intrauterine growth retardation, leucopenia, neutropenia, increased circulating rbc and thrombocytopenia during the early neonatal period, these babies should be closely monitored so as to facilitate early detection and management of sepsis and bleeding tendencies in order to attempt to provide these babies with decreased morbidity and improved growth, development and survival.

\section{REFERENCES:}

1. Bray JE, Grimm JK, Little VA. Neonatal manifestations of severe maternal hypertension occurring before the thirty sixth week of pregnancy. J Pediatr. Feb 1982;100(2):265-71

2. Bhatt YR, Cheri and CS. Neonatal thrombocytopenia associated with maternal pregnancy induced hypertension. Indian J Pediatr. Jun 2008; 75(6):571-3.

3. Raizada N, Lal A, Bhatia RC, Jain BK, Chander K, Goyal A. Neonatal thrombocytopenia due to pregnancy induced hypertension. Indian J Pediatr. 1996; 63:226-8.

4. Ligia Maria Suppo de Souza Rugolo, Maria Regina Bentlin and Cleide Enoir Petean Trindade. Preeclampsia: Effect on the fetus and newborn. Neo Reviews. Apr 2011; 12(4): e198-e206.

5. Kim HY, Sohn YS, Lim JH. Neonatal outcome after preterm delivery in HELLP syndrome. Yonsei Med J. 2006; 47(3):393-8.

6. Procianoy RS, Silveira RC, Mussi-Pinhata MM. Brazilian network on neonatal research. Sepsis and neutropenia in very low birth weight infants delivered of mothers with preeclampsia. J Pediatr. 2010; 157(3):434-8.

7. Saarinen UM, Siimes MA. Developmental changes in red blood cells and indices of infants after exclusion of iron deficiency by laboratory criteria and continuous iron supplementation. J Pediatr. 1978; 92:412-6.

8. Marwaha N, Marwaha RK, Narang A. Routine hematological values in term newborns. Indian Pediatr. 1992;29:1095-9.

9. Sivakumar S, Bhat BV, Badhe BA. Effect of pregnancy induced hypertension on mothers and their babies. Indian J Pediatr. 2007; 74(7):623-5.

10. Shivhare K, Chawla K, Khan MA, Mathur PS. Effect of maternal toxemia on total hemoglobin, foetal hemoglobin and nucleated red blood cells in cord blood. Indian J Pediatr. 1976; 43:349.

11. Philip AG, Tito AM. Increased nucleated red blood counts in small for gestational age infants with very low birth weight. Am J Dis Child. 1989; 143:164-9. 
12. Fraser SH, Tudehope D. Neonatal neutropenia and thrombocytopenia following maternal hypertension. Journal of pediatrics and child health. 1995; 32:31-4.

13. Pritchard JA, Cunningham FG, Pritchard SA, Mason RA. How often does maternal preeclampsia incite thrombocytopenia in the fetus? Obstet Gynecol. 1987; 69: 292-295.

14. Thiagarajah S, Bourgeois FJ, Harbert GM Jr, Caudle MR. Thrombocytopenia in preeclampsia: associated abnormalities and management principles. Am J Obstet Gynecol Sep 1984; 150(1):1-7.

15. Cristina C, Santos-Silva A, Belo L. Inflammatory disturbances in preeclampsia: relationship between maternal and umbilical cord blood. J Pregnancy. Epub May 2012; 68:43-4.

16. Tsao PN, Teng RJ, Tang JR, Yau KT. Granulocyte colony stimulating factor in the cord blood of premature neonates born to mothers with pregnancy induced hypertension. J Pediatr. 1999; 135(1):56-9.

17. Rapoport AP, Abboud CN, DiPersio JF. Granulocyte - macrophage colony - stimulating factor [GM-CSF] and Granulocyte colony stimulating factor [G-CSF]: receptor biology, signal transduction and neutrophil activation. Blood Rev. March1992; 6(1):43-57.

18. Doron MW, Makhlouf RA, Katz VL. Increased incidence of sepsis at birth in neutropenic infants of mothers with preeclampsia. J Pediatr. 1994; 125:452-8.

19. Engle WD, Rosenfeld CR. Neutropenia in high risk neonates. J Pediatr. 1984; 105:982.

Table 1: Pregnancy and delivery details of cases and control.

\begin{tabular}{|c|c|c|}
\hline Parameter & Cases (n=75) & Control (n=75) \\
\hline Maternal age (Mean) & $22.88 \mathrm{yrs}$ & $22.76 \mathrm{yrs}$ \\
\hline Booked cases & $96 \%$ & $98.7 \%$ \\
\hline Mean systolic B.P. & $161.11 \mathrm{mmHg}$ & $120.16 \mathrm{mmHg}$ \\
\hline Mean diastolic B.P. & $103.92 \mathrm{mmHg}$ & $78.83 \mathrm{mmHg}$ \\
\hline Operative delivery & $64 \%$ & $40 \%$ \\
\hline Male: Female ratio & $48: 27$ & $40: 35$ \\
\hline Gestational Age (Mean) & $37.39 \mathrm{wks}$ & $37.39 \mathrm{wks}$ \\
\hline Birth weight (Mean) & $2.56 \mathrm{kgs}$ & $2.71 \mathrm{kgs}$ \\
\hline Small for gestational Age & $25.4 \%$ & $14.7 \%$ \\
\hline
\end{tabular}


Table 2: Comparison of babies study variables in two groups.

\begin{tabular}{|c|c|c|c|}
\hline Investigations & Cases (n=75) & Controls (n=75) & p value \\
\hline $\mathrm{Hb}$ & $14.83 \pm 2.08$ & $15.22 \pm 2.06$ & 0.252 \\
\hline $\mathrm{PCV}$ & $44.52 \pm 6.05$ & $45.50 \pm 5.79$ & 0.313 \\
\hline Red cell count & $4.13 \pm 0.59$ & $4.32 \pm 0.61$ & 0.058 \\
\hline $\mathrm{MCV}$ & $107.96 \pm 7.47$ & $105.43 \pm 5.03$ & 0.016 \\
\hline $\mathrm{MCH}$ & $36.13 \pm 2.76$ & $35.32 \pm 2.29$ & 0.052 \\
\hline $\mathrm{MCHC}$ & $33.44 \pm 1.71$ & $33.46 \pm 1.46$ & 0.951 \\
\hline $\mathrm{nRBC}$ & $13.33 \pm 15.24$ & $2.44 \pm 2.37$ & $<0.001^{* *}$ \\
\hline TLC & $9.31 \pm 3.72$ & $12.61 \pm 4.64$ & $<0.001^{* *}$ \\
\hline Neutrophils & $47.4 \pm 18.21$ & $62.13 \pm 11.55$ & $<0.001^{* *}$ \\
\hline Lymphocyte & $44.06 \pm 17.90$ & $32.59 \pm 26.83$ & $<0.002^{* *}$ \\
\hline ANC & $5061.85 \pm 3429.7$ & $8261.06 \pm 3424.2$ & $<0.001^{* *}$ \\
\hline Platelet count & $1.42 \pm 0.78$ & $2.09 \pm 0.56$ & $<0.001^{* *}$ \\
\hline
\end{tabular}

Table 3: Comparison of babies study variables according to PIH category.

\begin{tabular}{|c|c|c|c|}
\hline Investigations & Gestational hypertension & Pre-eclampsia & Eclampsia \\
\hline $\mathrm{Hb}$ & $15.36 \pm 2.13$ & $14.56 \pm 2.02$ & $14.36 \pm 2.06$ \\
\hline $\mathrm{PCV}$ & $45.28 \pm 6.00$ & $43.96 \pm 6.14$ & $44.39 \pm 6.23$ \\
\hline Red cell count & $4.27 \pm 0.56$ & $4.04 \pm 0.59$ & $4.06 \pm 0.67$ \\
\hline $\mathrm{MCV}$ & $106.46 \pm 7.34$ & $108.01 \pm 7.54$ & $111.63 \pm 6.86$ \\
\hline $\mathrm{MCH}$ & $36.04 \pm 2.01$ & $35.81 \pm 3.34$ & $37.41 \pm 2.07$ \\
\hline $\mathrm{MCHC}$ & $33.93 \pm 0.97$ & $33.13 \pm 2.22$ & $33.21 \pm 0.94$ \\
\hline $\mathrm{nRBC}$ & $10.07 \pm 10.26$ & $16.28 \pm 19.47$ & $12.00 \pm 6.71$ \\
\hline $\mathrm{TLC}$ & $9.95 \pm 3.43$ & $8.42 \pm 3.40$ & $10.61 \pm 4.91$ \\
\hline Neutrophils & $48.83 \pm 20.09$ & $46.52 \pm 17.41$ & $46.65 \pm 17.18$ \\
\hline Lymphocyte & $42.25 \pm 20.56$ & $45.46 \pm 16.56$ & $44.08 \pm 15.93$ \\
\hline Platelet count & $1.50 \pm 0.76$ & $1.40 \pm 0.85$ & $1.29 \pm 0.63$ \\
\hline
\end{tabular}

Table 4: Pearson correlation between neonate platelet count with maternal SBP and DBP in cases.

\begin{tabular}{|c|c|c|c|c|c|}
\hline Maternal BP & \multicolumn{5}{|c|}{ Neonate platelet count } \\
\hline & $\begin{array}{c}<1 \text { lakh } \\
(\mathrm{n}=32)\end{array}$ & $\begin{array}{c}1.0-1.50 \text { lakh } \\
(\mathrm{n}=11)\end{array}$ & $\begin{array}{c}1.50-2.0 \text { lakh } \\
(\mathrm{n}=11)\end{array}$ & $\begin{array}{c}2.0-3.0 \text { lakh } \\
(\mathrm{n}=19)\end{array}$ & $\begin{array}{c}>3.0 \text { lakh } \\
(\mathrm{n}=2)\end{array}$ \\
\hline SBP (mm Hg) & & & & & \\
\hline$\bullet<140$ & $0(0 \%)$ & $0(0 \%)$ & $0(0 \%)$ & $0(0 \%)$ & $0(0 \%)$ \\
\hline$\bullet 140-149$ & $7(21.9 \%)$ & $6(54.5 \%)$ & $5(41.7 \%)$ & $7(38.9 \%)$ & $0(0 \%)$ \\
\hline$\bullet 150-159$ & $13(40.6 \%)$ & $1(9.1 \%)$ & $2(16.6 \%)$ & $3(16.7 \%)$ & $0(0 \%)$ \\
\hline$\bullet \quad 160$ & $12(37.5 \%)$ & $4(36.4 \%)$ & $5(41.7 \%)$ & $8(44.4 \%)$ & $2(100 \%)$ \\
\hline DBP (mm Hg) & & & & & \\
\hline$\bullet<90$ & $0(0 \%)$ & $0(0 \%)$ & $0(0 \%)$ & $0(0 \%)$ & $0(0 \%)$ \\
\hline$\bullet \quad 90-99$ & $9(28.1 \%)$ & $3(27.3 \%)$ & $5(45.5 \%)$ & $6(31.6 \%)$ & $0(0 \%)$ \\
\hline$\bullet 100-109$ & $11(34.4 \%)$ & $4(36.4 \%)$ & $4(36.4 \%)$ & $8(42.1 \%)$ & $0(0 \%)$ \\
\hline$\bullet>110$ & $12(37.5 \%)$ & $4(36.4 \%)$ & $2(18.2 \%)$ & $5(26.3 \%)$ & $2(100 \%)$ \\
\hline
\end{tabular}




\section{ORIGINAL ARTICLE}

\section{AUTHORS:}

1. Prekshya L. Prakash

2. P. Sunil Kumar

3. M. Venkata Murthy

4. K.R. Haricharan

\section{PARTICULARS OF CONTRIBUTORS:}

1. Resident, Department of Pediatrics, Adichunchanagiri Institute of Medical Science, B.G. Nagara, Nagamangala Taluk, Mandya, Karnataka, India.

2. Assistant Professor, Department of Pediatrics, Adichunchanagiri Institute of Medical Science, B.G. Nagara, Nagamangala Taluk, Mandya, Karnataka, India.

3. Professor, Department of Pediatrics, Adichunchanagiri Institute of Medical Science, B.G. Nagara, Nagamangala Taluk, Mandya, Karnataka, India.
4. Assistant Professor, Department of Pediatrics, Adichunchanagiri Institute of Medical Science, B.G. Nagara, Nagamangala Taluk, Mandya, Karnataka, India.

\section{NAME ADDRESS EMAIL ID OF THE CORRESPONDING AUTHOR:}

Dr. P. Sunil Kumar,

Door No. 1412,

Behind Guru Theatre,

B.M. Road, Hassan - 573201,

Karnataka, India.

Email-dr_pusuku@yahoo.co.in

Date of Submission: 12/07/2013.

Date of Peer Review: 13/07/2013.

Date of Acceptance: 17/08/2013.

Date of Publishing: 20/08/2013 